where the shop, for which they may be responsible, stands in regard to the plants listed, will have food for thought in the fact that the largest shop, based on people employed, achieves barely half the turnover per employee achieved by the smallest shop, and little more than one-third of that achieved by the plant which is less than one-third its size. Of course, the comparative nature of the work, which the author's do not give, could, in part, explain these wide variations. Unfortunately, they accord too closely with Britain's general pattern, and it is to be hoped that in bringing these figures up to date in later editions the authors will give similar figures culled from the United States, to the benefit of their British and American readers alike.

The rapid advances in techniques for anodizing aluminium for exterior architectural work, that have been made over recent years, suggest that both revision and amplification of the authors' references to this subject would merit attention in future editions. Some comment, in the paragraphs on trichloroethylene degreasing, on the troubles experienced by some shops, which have used this process for cleaning aluminium intended for exterior architectural work, would also bo welcomed in later editions. The short paragraph devoted to dyes for anodized coatings is too short to do the authors justice.

The attention to $B S .3382$ in the chapter on plating threaded parts is surely inspired. It is becoming increasingly clear that the requirements of this specification are no more stringent than the minimum required to sustain and accelerate the growth of this market, which seems to have expanded more strongly since the publication of $B S$ S. 3382 than ever before.

The formulæ, so generously set out, cover much valuable information that, in the not distant past, would have been shrouded in commercial secrecy. Permission to publish such data displays confidence in the belief that what benefits the industry must benefit its members, and evokes the hope that later editions will include a glossary of troubles that platers must expect to meet and suggested methods to avoid or overcome them.

In conclusion, it must be said again that the anthors have achieved in full their aim to produce "a handbook for those whose duty it is to design, erect, majntain, or run an electrodeposition plant" and, without doubt, this book should be on the shelves of all whose work is covered by the author's' description.

J. Fox-Wintuams

\section{BIOLOGICAL CLOCKS}

\section{The Physiology of Diurnal Rhythms}

By Janet E. Harker. (Cambridge Monographs in Experimental Biology, No. 13.) Pp. vii + 114. (Cambridge: At the University Press, 1964.) 20s. net; 3.95 dollars.

DLANTS and animals show diurnal (or circadian) rhythms in their physiological processes and behaviour. In a natural environment, the timing of the phases of any rhythm is, within a pattern imposed by the genetical constitution of the organism (to use Dr. Harker's own words), primarily affected by light conditions, including both intensity and photofraction. But superimposed on the effects of light, variations may be induced by fluctuating temperature and humidity, amount of food present, age and sex of the organism, and the number of other animals of the same species present. However, once the phases of a circadian rhythm have been set, the rhythm will persist under constant conditions for many months or even throughout the life-time of an animal.

The phenomenon can be explained on alternative hypotheses. Either there is an endogenous mechanism, or there are external time signals which are perceptible to the organism, but not to the research worker. In a search for time-cues which would permit the latter hypothesis, F. A. Brown and his colleagues have invoked and investi- gated the roles of lunar and solar cycles and of changes in terrestrial magnetism and barometric pressure. According to Brown, for example, the diurnal pattern of oxygen consumption of organisms in a pressure-controlled chamber can be affected by the barometric pressure one to seven days ahead.

Dr. Harker's stated view is that neithor theory can at present be proved. No evidence has been recorded to disprove the effects observed by Brown, even though his contention is not accepted by the majority of workers. Moreover, the adaptive significance of a short endogenous rhythm is not obvious; an immediate reaction to the prevailing environment would have many advantages. Nevertheless, the tenor of Dr. Harker's book supports the view that the ultimate controlling system of circadian. rhythms is to be found within the organism, even though phasing factors are supplied by the environment. There seems to be little doubt, she says, that somo clock-like cellular mechanism exists which is responsible for the observed physiological and biological rhythms. On another level she cites her own beautiful demonstration that a cockroach made arrhythmic in locomotor activity by keeping it for a long period in continuous light develops a diurnal rhythm when joined parabiotically with a rhythmically active eockroach which has been kept in alternating 12 -hour periods of light and darkness. The source of the activity rhythm has been traced to a secretion of a group of neurosecretory cells lying on either sid $\theta$ of the sub-cesophageal ganglion.

This attempt to summarize the major argument of $\mathrm{D}_{\mathrm{r}}$. Harker's monograph does not do full justice to its comprehensiveness or its logical presentation. The field of descriptive and experimental work on diurnal rhythms is explored and documented; their significance and the possible nature of biological clocks is fully discussed. The book should initiate a sphere of readers into an important branch of biology which has only developed within the past two or three decades. F. J. Ebisva

\section{RESEARCH ON WATER POLLUTION}

Advances in Water Pollution Research

(Proceedings of the International Conference held in London, September 1962.) Edited by B. A. Southgate, Prof. W. W. Eckenfelder and Prof. E. A. Pearson. Vol. 1: Pp. xliii +437. Vol. 2: Pp. vi 578 . Vol. 3: Pp. vit 437. (London and New York: Pergamon Press, 1964.) 300s. net por set.

THE first International Conference on Water Pollution was convened with a view to disseminating information on recent advances in knowledge resulting from research in relevant ficlds, and was a logical outcome of the steady growth in the effort being devoted in an increasing number of countries to pollution prevention and control. The Conference was organized into three sections, the proceedings of each of which-comprising the sixteen papers presented and the accompanying discussion-form the main subject-matter of a separate volume. The first of these is concerned with the problem of pollution in streams and rivers, the second with the development of methods for treatment of effuents and of the solids derived from them, and the third with the disposal of effluents in estuaries and in the sea.

It is abundantly clear from these proceedings that water pollution research presents those concerned in it with a fascinating variety of problems covering a wide range of complex chemical, physical and biological phenomena. In the first volume the subjects covered include such diverse topics as the correlation of masstransfer coefficients for the absorption of atmospheric oxygen in rivers with their hydraulic characteristics, the effects of liquid shear on invertebr'ates, the response of fish to temperature gradients, the occurrence of patho- 